\title{
Prophylaxis of malaria by Artemisia infusions:The key role of lysine
}

\begin{abstract}
There are many anecdotic reports or clinical trials describing the prophylactic effect of Artemisia plants against malaria and this has been documented in several peer reviewed papers. But the mechanism of this action has not been elucidated. The prophylactic effect is not due to artemisinin or its derivatives. We made a literature survey to find possible explanations.
\end{abstract}

Volume 9 Issue 5 - 202।

\author{
Pierre Lutgen \\ IFBV-BELHERB BP 98, Luxembourg
}

Correspondence: Pierre Lutgen, IFBV-BELHERB BP 98 , Niederanven, Luxembourg, Email lutgenp@gmail.com

Received:September 15, 202 I | Published: October 08, 202 I

\section{Introduction}

Since several years we try to understand why Artemisia infusions show a very efficient prophylaxis against malaria. This has been noticed in clinical trials and anecdotic reports in several African countries. Patrick Ogwang in his seminal work finds that Artemisia annua infusion consumed once a week is effective in preventing multiple episodes of malaria attacks and its mode of action may involve stimulation of white blood cells production especially monocytes. ${ }^{1}$ We have proposed several hypotheses, but were so far unable to verify them in vivo., Another hypothesis was based on the oxidative weakening of sporozoites by NO generated by arginine. Scientific papers on this topic are scarce. ${ }^{4,5}$ Another explanation for the prophylactic effect is resting on the high concentration of fatty acids in medicinal plants, and particularly polyunsaturated fatty acids (PUFA). Preliminary studies had indicated to a research team in Norway a suppressive influence of fish oils on rodent malaria. ${ }^{6}$

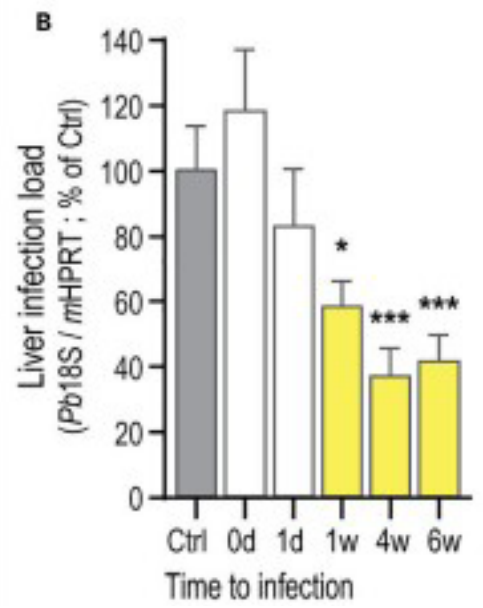

Figure I The drinking water (Ctrl) was replaced by RKV-supplemented water on the day of Plasmodium berghei sporozoite injection ( $0 \mathrm{~d})$, or I day, I week, 4 weeks, or 6 weeks before infection.

\section{The unsuspected role of amino acids}

A recent paper from Portugal has studied the role of amino acids in depth and comes to very convincing conclusions. ${ }^{7}$ We extract one figure from their paper. Drinking an aqueous solution of argininelysine-valine (RKV) several weeks before the infection significantly reduces the liver infection load (Figure 1).
In another figure they clearly show that the efficacy of lysine is much higher than that of valine and arginine. The role of amino acids in malaria infections has mostly been ignored and it is difficult to find papers on this subject. ${ }^{89}$ To gain insight into the mechanism of malarial hemozoin formation, these authors examined the effect of amino acids on beta hematin formation in vitro. Surprisingly some of these amino acids like arginine, histidine, lysine showed a significant inhibition. In contrast beta-hematin formation was enhanced by leucine, isoleucine, valine and methionine.

Breast milk protects neonates against malaria and other diseases during six months. Colostrum is rich in zinc and potassium, but it is also rich in lysine. A systematic review in human milk from 13 countries showed that lysine declined in the two first months of lactation and then remained relatively constant (from 148 to $68 \mathrm{mg} / 100 \mathrm{ml}$ ). ${ }^{10} \mathrm{~A}$ survey made in 1996 showed that the essential amino acid lysine may be lacking in nutrition for many areas of the world. Average lysine supply was $6662 \mathrm{mg}$ /day in Western Europe and 2542 in subSaharan Africa. This is below the FAO/WHO minimal requirement of 2840 $\mathrm{mg} /$ day and might enhance the susceptibility of Africans to Anopheles mosquito bites. And to some extent counterbalance the immunity acquired by multiple malaria infections. ${ }^{11}$

Artemisia plants are rich in arginine, lysine and valine. ${ }^{12,13}$ According to Brisibe EA the lysine content in Artemisia annua is $2.17 \mathrm{~g} / 100 \mathrm{~g}$. Checking for other plants we find that Camellia sinensis (green tea) only contains $0.02 \mathrm{~g} / 100 \mathrm{~g}$. Greentea has no antimalarial properties. ${ }^{14}$ And that the medicinal plants (dry) leaves. Euphorbia thymifolia only contains $0.14 \mathrm{~g} / 100 \mathrm{~g}$ of lysine, Zinziber officinale $0.14 \mathrm{~g} / 100 \mathrm{~g}$ and Pavetta indica $0,30 \mathrm{~g} / 100 \mathrm{~g}^{15}$ And for Vernonia amygdalina $0.05 \mathrm{~g} / 100 \mathrm{~g}$.were found. All values lower than for Artemisia. ${ }^{16}$

As noted previously, Artemisia plants are rich in both lysine and zinc. In malaria infections it was noticed that there is a strong synergy between zinc and arginine in the inhibition of hemozoin (Mutaz Akkawi, Al Quds University, Palestine, personal communication). A similar positive synergy has been noticed for zinc and lysine in improving the immune system. In a study in Indonesia, infection rate for several diseases (diarrhea, influenza, pharyngitis...) was lower in zinc group and zinc + lysine group $(\mathrm{p}<0.065)$ compared to control group. Zinc + lysine supplementation also increased CD4 count and had better effect compared to zinc supplementation alone. ${ }^{17}$

In France a comparative study was conducted on the anti-malarial effects of Artemisia annua (containing artemisinin) and Artemisia 
afra (lacking artemisinin) plant infusions in vitro against the asexual erythrocytic stages of Plasmodium falciparum and the preerythrocytic (i. e., liver) stages of various Plasmodium species. Low concentrations of either infusion accounted for significant inhibitory activities across every parasite species and stage studied. These antiplasmodial effects were essentially artemisinin-independent and were additionally confirmed by observations of the parasite apicoplast and mitochondrion. In particular, the infusions significantly incapacitated sporozoites. This seminal work requires further studies on the role of amino-acids and particularly lysine on the liver stages of malaria infections. Publications in this field of research are scarce. But the role of amino acids is complex. Arginine is an amino acid that has been shown in nonclinical studies to be essential in the life cycle of many viruses. Which would imply that Artemisia infusions rich in arginine and other amino acids might enhance Covid infections. ${ }^{18}$

\section{Conclusion}

The amino acid lysine in conjunction or not with arginine plays a key role in malaria prophylaxis. Further in-depth studies and clinical trials on this subject should be encouraged.

\section{Acknowledgments}

None.

\section{Conflicts of interest}

Authors declare that there is no conflict of interest.

\section{References}

1. Ogwang PE, Ogwal JO, Simon Kasasa, et al. Use of Artemisia annua L. Infusion for Malaria Prevention: Mode of Action and Benefits in a Ugandan Community. British Journal of Pharmaceutical Research. 2011;1(4):124-132.

2. Munyangi J, Gisenya P, Ogwang P, et al. An unexpected, revolutionary property of Artemisia infusions: immunoglobulins in the skin lead to a longlasting prophylaxis. Pharm Pharm Pharmacol Int J. 2020;8(1):46-62.

3. Lutgen P. Prophylaxis with Artemisia annua is very efficient: The Role of Chelators. Pharm Pharmacol Int J. 2017;5(5):00138.

4. Nüssler A, Drapier JC, Rénia L, et al. L-arginine-dependent destruction of intrahepatic malaria parasites in response to tumor necrosis factor and/or interleukin 6 stimulation. Eur J Immunol. 1991;21(1):227-230.
5. Nüssler AK, Rénia L, Mazier D. In vivo induction of the NO nitric oxide pathway in hepatocytes after injection with irradiated malaria sporozoites, malaria blood parasites or adjuvants. Eur J Immunol. 1993;23(4):882-887.

6. Fevang P, Sääv H, Høstmark AT. Dietary fish oils and long-term malaria protection in mice. Lipids. 1995;30(5):437-441.

7. Meireles P, Brás D, Fontinha D, et al. Elimination of Hepatic Rodent Plasmodium Parasites by Amino Acid Supplementation. iScience. 2020;23(12):101781.

8. Uyen DT, Huy NT, Trang DT, et al. Effects of amino acids on malarial heme crystallization. Biol Pharm Bull. 2008;31(8):1483-1488.

9. Krishnan A, Soldati-Favre D. Amino Acid Metabolism in Apicomplexan Parasites. Metabolites. 2021;11(2):61.

10. Zhang Z, Adelman AS, Rai D, et al. Amino acid profiles in term and preterm human milk through lactation: a systematic review. Nutrients. 2013;5(12):4800-4821.

11. Peter LP. World essential amino acid supply with special attention to South-East Asia. Food and Nutrition Bulletin. 1996;17(3):1-31.

12. Ochkur O, Alla K, Sydora N. Amino acids composition of Artemisia L. genus species subgenus Dracunculus Bess. from Ukrainian flora. The Pharma Innovation Journal. 2013;2(3):64-67.

13. Brisibe EA, Umoren UE, Ferreira E, et al. Nutritional Characterisation and Antioxidant Capacity of Different Tissues of Artemisia Annua L. Food Chemistry. 2009;115(4):1240-1246.

14. Chu DC, Juneja LR. General Chemical Composition of Green Tea and its Infusion. In: Chemistry and Applications of Green Tea. CRC Press: Boca Raton; 1997. 13-22 p.

15. Prasad K. HPLC Analysis of Amino Acid and Antioxidant Composition of Three Medicinal Plants of (Pithoragarh) Uttarakhand Himalayas. J Anal Pharm Res. 2017;6(5):00186.

16. Sodamade A. Proximate Analysis, Mineral Content, Amino Acid Composition and Functional Properties of Vernonia amygdalina Vegetable Leaf Protein Concentrates. Greener Journal of Agricultural Sciences. 2013;3(3):204-210.

17. Sugeng MW, Adriani M, Wirjatmadi B. The Effect of Zinc and Lysine Supplementation on Infection Rate and CD4 Count In Elderly. Biochem Physiol. 2015;S5:002.

18. Grimes JM, Khan S, Badeaux M, et al. Arginine depletion as a therapeutic approach for patients with COVID-19. Int J Infect Dis. 2021;102:566-570. 